\title{
Investigation of Liquid Smoke's Composition from Peach Tree Wood using GC-mass and its Microbial and Physiochemical Properties on Hotdogs
}

\author{
P MAHASTI SHOTORBANI ${ }^{1}$, P MAJIDI $^{2}$ and H AHARI ${ }^{3 *}$ \\ 'Department of Food Science and Technology, Islamic Azad University, \\ Science and Research Branch, Tehran,Iran. \\ ${ }^{2} \mathrm{M}$.Sc in Food Science and Technology, Islamic Azad University, \\ Science and Research Branch, Tehran, Iran. \\ ${ }^{3}$ Department of Food Science and Technology, Islamic Azad University, \\ Science and Research Branch, Tehran, Iran. \\ *Corresponding author E-mail: Dr.h.ahari@gmail.com \\ http://dx.doi.org/10.13005/ojc/330151
}

(Received: July 01, 2016; Accepted: January 01, 2017)

\begin{abstract}
Fumigation is one of the oldest methods of meat preservation, and it has been used to improve sensory properties of fish and other meat products for over 30 years. Liquid smoke has antimicrobial and antioxidant activities, in addition to its sensory properties. In this research, the effects of liquid smoke made from peach tree wood were evaluated. In the first step, the compound composition of liquid smoke was evaluated by a GC-mass system. The primary components of this essential oil consisted of phenolic and acidic compounds. In addition, the ascorbic acid was removed from the hotdog formulation, and the amount of applied nitrite and nitrate were reduced to one half $(60 \mathrm{ppm})$. In the second phase of the research, hotdog samples containing $0.4 \%$ and $0.6 \%$ liquid smoke were evaluated for antimicrobial ability, antioxidant capability, sensory properties, moisture reduction, and $\mathrm{pH}$ over a period of $14 \mathrm{~d}$. The results of this research showed that liquid smoke, in a concentration of $0.6 \%$, has a significant effect in the reduction of the microbial load (total count of Clostridium perfringens) in hotdog samples over $14 \mathrm{~d}(p<0.0001)$, and it is effective in oxidation reduction by $\mathrm{d} 7(p=0.0051)$, and $14(p=0.0001)$, while also significantly reducing the product's moisture on $\mathrm{d} 1(p=0.0269)$ through $\mathrm{d} 14(p=0.05)$. In colorimetric tests, liquid smoke did not have any significant effect on the $b^{*}$ factor, but concentrations of $0.4 \%$ liquid smoke on $d 14$ $(p=0.0313)$ and $0.6 \%$ liquid smoke on $\mathrm{d} 1(p=0.0355), \mathrm{d} 7$, and $\mathrm{d} 14(p=0.0003)$ affected the $\mathrm{a}^{*}$ factor, and the concentration of $0.6 \%$ affected the $L^{*}$ factor, in comparison with the control sample on $\mathrm{d} 1, \mathrm{~d} 7(p=0.0451)$, and $\mathrm{d} 14(p=0.027)$. In pH tests, both concentrations of $0.4 \%$ liquid smoke on $\mathrm{d} 1(p=0.0133), \mathrm{d} 7(p=0.0422)$, and $\mathrm{d} 14(p=0.005)$, and $0.6 \%$ liquid smoke $(p<0.0001)$ significantly reduced the $\mathrm{pH}$ in comparison to the control samples. The statistical results from the sensory evaluation test showed that between all applied concentrations $(0.01 \%, 0.02 \%, 0.04 \%$ and $0.06 \%$ ) of liquid smoke, the two concentrations of $0.06 \%$ and $0.4 \%$ had the best scores among the panelists and qualified for the next phase of the research. General results of this study showed that in addition to sensory properties' improvement, liquid smoke has antimicrobial and antioxidant activity, and the ability to reduce $\mathrm{pH}$, due to the presence of phenolic and acidic compounds, and this ability increases with greater concentrations of the liquid smoke.
\end{abstract}

Keywords: GC-mass. liquid smoke, hotdog, sausage, $70 \%$, antioxidant. 


\section{INTRODUCTION}

Meat products are one of the most popular food products and comprise a large portion of the world's market. These products are categorized in the class of perishable foods and have the potential of microbial spoilage and oxidation. With the aim of achieving more marketability in addition to providing better shelf life, a preferred method for increasing shelf life should preferably improve the taste and color of the product, and fumigation is one of the best methods to achieve this. However, the traditional fumigation methods contain a group of harmful compounds known as PAHs. ${ }^{1}$ Because liquid smoke is nearly PHA-free, it has some advantages in comparison to traditional smoke, along with others, such as uniformity of color in the final product, being environmental friendly, and easy clean up, as fumigation rooms can be easily cleaned by water with no need for any chemical detergent. ${ }^{1}$

Liquid smoke contains phenolic, carbonyl, and acidic compounds. Carbonyls play a large role in the improvement of meat color, while phenolic compounds are effective in improving the product's flavor. Phenols, guaiacol, and syringol are some well-known phenolic compounds. Guaiacol and syringol are related to flavor and aroma of the smoke, respectively. There are also some other compounds, such as lactones and formaldehydes, which affect the smoke's aroma and flavor. The phenolic portion of the liquid smoke has antioxidant effects, and acidic compounds of the liquid smoke also have an antimicrobial effect. The goal of liquid smoking consists of enhancing the antimicrobial and antioxidant activities, in addition to the added aromatic properties. ${ }^{2}$

Many researchers have investigated the properties of liquid smoke. Gonulalan et al. (2003) examined the effect of liquid and traditional smoke on microbial, chemical, and organoleptic properties of cow tongue, over a period of $30 \mathrm{~d}$ at a storage temperature of $4 \pm 1^{\circ} \mathrm{C}$. Siskos et al. (2007) inquired into the effects of liquid smoke on the microbial load of salmon fish fillets. Martin (2010) investigated the effects of liquid smoke on Listeria monocytogenes in inoculated frankfurters over $140 \mathrm{~d}$, and CaiKe-Zhou et al. (2011) discussed the effect of liquid smoke made from American hickory wood on organoleptic characteristics, shelf life, and oxidation. Schwert et al. (2011) evaluated the effect of liquid and traditional smoke on the oxidation of lipids and proteins, sensory characteristics, and the color of cooked Brazilian sausage in temperatures of $5^{\circ} \mathrm{C}$ and $20^{\circ} \mathrm{C}$ over $120 \mathrm{~d}$ Zuraida, Sukarno, and Budijanto (2011) investigated the impact of liquid smoke in concentrations of $0 \%$, $3 \%, 5 \%$ and $7 \%$ over a period of $0 \mathrm{~d}, 5 \mathrm{~d}, 10 \mathrm{~d}$, and 15 $\mathrm{d}$ on the water content, protein content, fat content, $\mathrm{pH}$, and total microbial count of meat balls. ${ }^{3-5}$

\section{MATERIALS AND METHODS}

\section{Treatment preparation}

All the treatments used in this research were prepared by the method and formulation of $70 \%$ meat hotdogs from the Solico (Iran) company, with applied nitrite and nitrate reduced to one half $(60 \mathrm{ppm})$ and with ascorbic acid removed from the formulation.

\section{Liquid smoke preparation}

Liquid smoke, made in Iran and produced from peach wood, was purchased and prepared in concentrations of $0.1 \%, 0.2 \%, 0.4 \%$ and $0.6 \%$.

\section{Treatments fumigation}

After preparation of the samples, they were combined with a percentage concentration of liquid smoke, prepared in the first phase, then cooked until the internal temperature of the product reached $72^{\circ}$ $\mathrm{C}$, then cooled to a temperature of $22^{\circ} \mathrm{C}$, and packed. The samples were evaluated on $d 1, d 7$, and $d 14$, after being kept in storage at temperatures of $0^{\circ}$ to $4^{\circ} \mathrm{C}^{6}$

\section{Sensory evaluation}

Samples' taste, aroma, color, palatability, and overall acceptability were evaluated. Sensory analysis using a five-point hedonic method was evaluated by 20 trained panelists.

\section{Determination of liquid smoke composition by GC-mass \\ A GC-mass made by Agilent Company} (US) in 2009, was set up with a $30 \mathrm{~m}$ long, HP$5 \mathrm{MS}$ capillary column with $0.25 \mathrm{~mm}$ internal diameter and a $25 \mathrm{~mm}$ internal layer thickness. The system was activated at an initial temperature of 
$50^{\circ} \mathrm{C}$. After two minutes at this temperature, the system's temperature was increased to $200^{\circ} \mathrm{C}$ at an acceleration of $3.5^{\circ} \mathrm{C}$ per minute. After two minutes at $200^{\circ} \mathrm{C}$, the temperature was increase to $280^{\circ} \mathrm{C}$ at an acceleration of $7^{\circ} \mathrm{C}$ per minute. The helium gas flow rate entering the column was $1 \mathrm{ml} /$ min. Liquid smoke components were separated by a chromatography column and after removal, the resulting gas entered into the mass spectrometry ionization source, and the graph was plotted by the detector's signal plotter as integrated peaks (Figure 1). ${ }^{7}$

\section{Microorganisms' total volume count (TVC)}

The microorganisms' TVC was carried out using a mixed-culture method on a plate count agar medium after three $\mathrm{d}$ of incubation at $30^{\circ} \mathrm{C}$, and the number of bacteria were reported as $\log _{10} \mathrm{CFU} / \mathrm{g} .^{8}$

\section{Clostridium perfringens inoculation Strain preparation and growth.}

A lyophilized strain of $C$. perfringens ${ }^{1}$ was purchased from the national organization of Scientific and Industrial Research (Iran) and activated by culturing in Reinforced Clostridial Broth, placed in anaerobic jars, and incubated for 48-72 $\mathrm{h}$ at $37^{\circ} \mathrm{C}$.

\section{Inoculating samples with the active strain and culturing}

Hotdog samples were inoculated with the activated strain of C. perfringens in the amount of $10^{8}$ $\mathrm{CFU} / \mathrm{g}\left(\mathrm{OD}_{620 \mathrm{~nm}}=1.2972\right)$. The inoculation method included culturing with a sterile syringe injection into various parts of the product, packaging, and incubation at specific temperatures designed for microbial tests. Expected dilutions were prepared and cultured, by mixing the culture in SPS Agar ${ }^{1}$ under anaerobic conditions, and incubated for 48-72 $\mathrm{h}$ at $37^{\circ} \mathrm{C}$. In the next step, formed colonies were counted, and the product's bacteria number was reported as log CFU/g.

\section{Physiochemical tests Colorimetric test}

Colorimetric tests were applied to cooked, fumigated samples by a HunterLab spectrophotometer, and the results were reported according to three factors: lightness $L^{*}$, redness $a^{*}$, and greenness $b^{*}$.

\section{Assessment of lipid oxidation}

In this case, the amount of TBARS was carried out by the method suggested by Pfalzgraf. Briefly, $10 \mathrm{~g}$ of the product sample and $20 \mathrm{~g}$ TCA were well-mixed in a homogenizer. Next, the sample was placed in a centrifuge at $1700 \mathrm{rpm}$ for $30 \mathrm{~min}$ and the solution separated using a filter paper (Whatman No. 1). In the next step, $2 \mathrm{ml}$ of the filtrate was mixed with $2 \mathrm{ml}$ of ( $300 \mathrm{ml}$ TBA in $100 \mathrm{ml}$ water) solution and placed in a $97^{\circ} \mathrm{C}$ hot water bath for 20 minutes. The samples were cooled immediately and the absorbance at $532 \mathrm{~nm}$ was read by a spectrophotometer. The amount of TBA was reported as $\mathrm{mg}$ of Malone aldehyde per $\mathrm{kg}$ of the product.

\section{pH measurement}

The $\mathrm{pH}$ measurement was performed using the method number 1028 standard. First, $10 \mathrm{~g}$ of the homogenized sample was well mixed to 100 $\mathrm{ml}$ distilled water for $1 \mathrm{~min}$, and then the $\mathrm{pH}$ was measured by a calibrated $\mathrm{pH}$ meter.

\section{Moisture measurement}

Five $g$ of the homogenous (double-minced) sample was placed in a $105^{\circ} \mathrm{C}$ oven up to the moment of reaching a stable weight.

\section{Statistical test and data analysis}

Data analysis was performed by an ANOVA test in SAS and EXCELL program software and comparison of means was done by Tukey's test.

\section{RESULTS}

In this research, application of liquid smoke as a preservative was investigated. In the first phase of the research, various concentrations of liquid smoke were applied for sensory evaluation, and in the second phase, the most preferable sample from the sensory testing was evaluated for antimicrobial ability, antioxidant capability, moisture reduction, and $\mathrm{pH}$.

\section{GC-mass test}

As mentioned in Table 1, the main compounds resulting from liquid smoke's gas chromatography were phenolic and acidic compounds, through which they could be responsible for $\mathrm{pH}$ reduction, antimicrobial. and antioxidant effects. 


\section{Sensory evaluation}

As shown in Table 2, scores given by evaluators for the taste, aroma, and color parameters represented samples that increased the liquid smoke amounts; the $0.6 \%$ and $0.4 \%$ concentrations were the first and second choices. These two concentrations showed a significant difference when compared to $1 \%$ and $2 \%$ concentrations $(p<0.05)$. Results showed that there was no significant difference between various concentrations of the liquid smoke, concerning color preference, but in general the $0.6 \%$ concentration showed better results. For the factors of palatability and overall acceptability, the concentration of $0.6 \%$ showed the best results. According to all factors of sensory evaluation, the concentrations of $0.6 \%$ and $0.4 \%$ revealed the best results, so they were chosen for the second phase of the research, where they were investigated, according to the aspects of color, moisture, $\mathrm{pH}$, antimicrobial capability and antioxidant activity.

\section{Results of the total bacterial count}

As shown in Graph 1, on the first d, the $0.4 \%$ liquid smoke, $0.6 \%$ liquid smoke, and control samples did not have any notable differences, but by d 7 and $d 14$, the difference between $0.6 \%$ samples and the other two became remarkable: the $0.6 \%$ samples reduced the total bacterial count to the lowest amount on $\mathrm{d} 14$, and a significant difference was visible between the $0.6 \%$ and $0.4 \%$ samples $(p<$ $0.05)$. This antimicrobial effect could be related to the phenolic and acidic compounds, which are present in liquid smoke.

\section{Results of the $C$. perfringens test}

According to Graph 2, the count of Clostridium colonies increased remarkably from d 1-7 across all of the samples. However, this increment was less in the $0.6 \%$ liquid smoke samples, and this finding shows that this sample could have made fewer colonies in by $\mathrm{d} 14$. Additionally, $0.6 \%$ liquid smoke samples maintained a significant difference from the other two samples: $0.4 \%$ liquid smoke and the control group $(p<0.05)$.

\section{Results of the colorimetric test}

Graphs 3, 4, and 5, and the colorimetric tests demonstrated that liquid smoke affects the $a^{*}$, $\mathrm{b}^{*}$, and $\mathrm{L}^{*}$ factors, and these effects are more in $\mathrm{a}^{*}$ than in the other two. Applying higher concentrations of liquid smoke caused the redness factor to increase in hotdog samples. Using liquid smoke also caused a small increment in the $b^{*}$ factor for the sample; but the difference was not significant, and the $b^{*}$ factor of the samples reduced smoothly over the period of the $14 \mathrm{~d}$. Application of liquid smoke caused a reduction in the $L^{*}$ factor of the samples, but there was no significant difference between the $0.4 \%$ liquid smoke samples and the control samples during the $14 \mathrm{~d}$. However, the samples with $0.6 \%$ liquid smoke showed a significant difference in this factor $(p<$ 0.05 ), which revealed that this concentration can cause darkening in the color of the product

\section{Results of the oxidation test}

Phenolic compounds in the essential oils can neutralize free radicals in the meat. Thiobarbituric acid (TBA) is widely used as an indicator of fat's secondary oxidation, which is the result of the second phase of autoxidation, during which the peroxides are oxidized into materials, such as aldehydes and ketones and these materials react with the TBA. Any two units of malondialdehyde (MDA) react with a single TBA, and this causes a pale pink color that can make a difference in the optical density. According to Graph 9, the oxidation rate of the control sample increased with a smooth acceleration over the period of the $14 \mathrm{~d}$, and using two of the mentioned concentrations caused reduction in this parameter. After a period of $7 \mathrm{~d}$, the difference between the $0.6 \%$ liquid smoke samples and the control samples were significant. After $14 \mathrm{~d}$, the difference between the $0.6 \%$ samples, the $0.4 \%$ samples, and the control samples were all significant $(p<0.05)$. In general, after $14 \mathrm{~d}$, the effect of the $0.6 \%$ liquid smoke samples were much greater than the $0.4 \%$ sampled in the reduction of oxidation, which could be due to the increased phenolic compounds in that concentration.

\section{Results of the $\mathrm{pH}$ test}

According to Graph 7, using liquid smoke caused a reduction in $\mathrm{pH}$, particularly in the $0.6 \%$ liquid smoke samples. In the control samples, we see a small reduction of $\mathrm{pH}$ in the first $7 \mathrm{~d}$, but in the second $7 \mathrm{~d}$, we observe an increase in $\mathrm{pH}$, which could be due to the breaking down of the nitrogenous compounds. In the period of the $14 \mathrm{~d}$, a significant difference appeared between the $0.6 \%$ liquid smoke samples and the $0.4 \%$ liquid smoke samples, and 
also between the $0.4 \%$ liquid smoke samples and the control samples $(p<0.05)$.

\section{Results of the moisture test}

According to Graph 8, liquid smoke reduced the amount of moisture remarkably over the period of the $14 \mathrm{~d}$, so there were significant effects between the $0.6 \%$ samples and the control samples from $d$ $1-14(p<0.05)$. This reduction in moisture could be due to the chemical bonding between liquid smoke and hydrogen ions (Arnim, Ferawati and Marlida, 2012).

Previous literature, which investigated the properties of liquid smoke in various products, showed that liquid smoke has both antioxidant and antimicrobial properties, and it causes reduction in $\mathrm{pH}$ and moisture, while also causing significant changes in products' colors. The main purpose of applying liquid smoke is to improve the aroma of the product. The liquid smoke was purchased from the Magnolia (Iran) factory, and it was produced from peach tree wood. The composition of compounds in peach tree wood liquid smoke showed that the ratio of the phenolic compounds were much more than the carbonyl compounds and other elements, and phenolic compounds were responsible for the aromatic properties of the smoke, and also the increased antimicrobial and oxidation properties, particularly at higher percentages of the liquid smoke. Liquid smoke was poor in carbonyl compounds, which were responsible for the color change of the product, so liquid smoke did not change the products' color significantly. The $\mathrm{pH}$ of the liquid smoke was 4.9 , which was due to the presence of the acidic compounds. According to this research, liquid smoke from peach tree wood had a remarkable inhibitory effect on the total $C$. perfringens count and reduced oxidation. Liquid smoke also reduced the $\mathrm{pH}$ and moisture content and had a positive effect on the

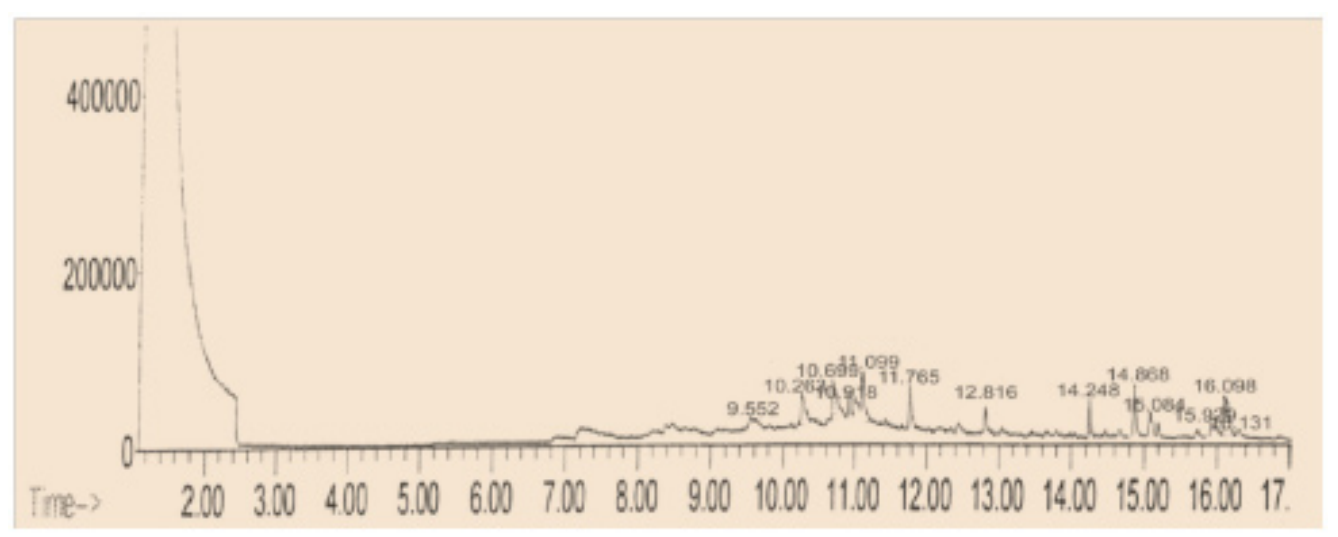

Fig. 1: Liquid smoke's gas chromatography

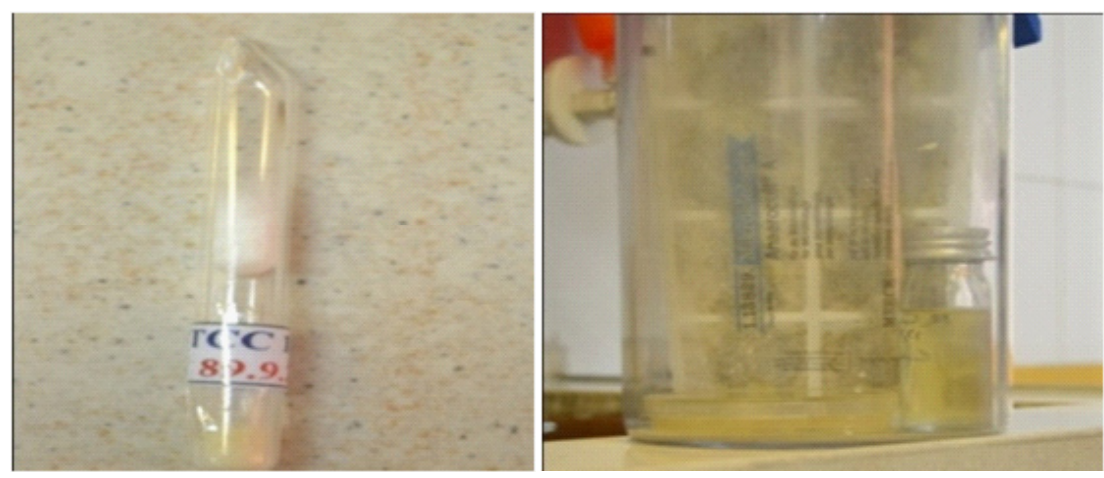

Fig. 2: (a) Photo of lyophilized strain; (b) Photo of the lyophilized strain in crystal broth medium inside anaerobic jars 
Table 1: Main compounds of liquid smoke in GC-mass test

Phenol

Ethyl guaiacol

2,6- Dimethoxy phenol

Vanillin

Benzaldehyde

4-hydroxy-3-methoxy

Alpha-lonone

1-Deoxy-1-(3-(2-methoxyphenyl)

4,5-Dimethoxy-2-methoxylphenol

Palmitic acid

Hexadecanoic acid

Valeric acid

Cyclooctanone

Cyclooctaneacetic acid products' color and other sensory properties. The most effective sample was the concentration of $0.6 \%$ liquid smoke..$^{7,9}$

Gonulalan et al. investigated the effect of liquid and traditional smoke on cow tongue. In this research, cow tongue meats were fumigated using two methods: traditional smoking and liquid smoking. They analyzed the microbial, chemical, and organoleptic tests at $\mathrm{d} 0, \mathrm{~d} 5, \mathrm{~d} 10, \mathrm{~d} 15$, and $d 30$. The results showed that in the period of $30 \mathrm{~d}$, both methods - traditional and liquid smoking — had a significant differences from control samples $(p<$ 0.05 ), and both smoking methods caused reduction in TBA and the microbial load, while improving the sensory properties. Clearly, that research corresponded with the results of liquid smoke testing in this research. ${ }^{10}$

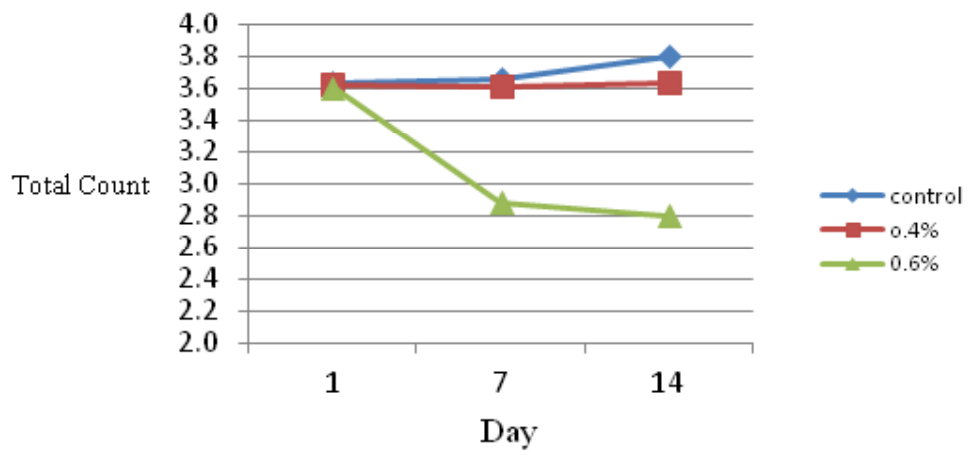

Graph 1: Effect of liquid smoke on total count of bacteria

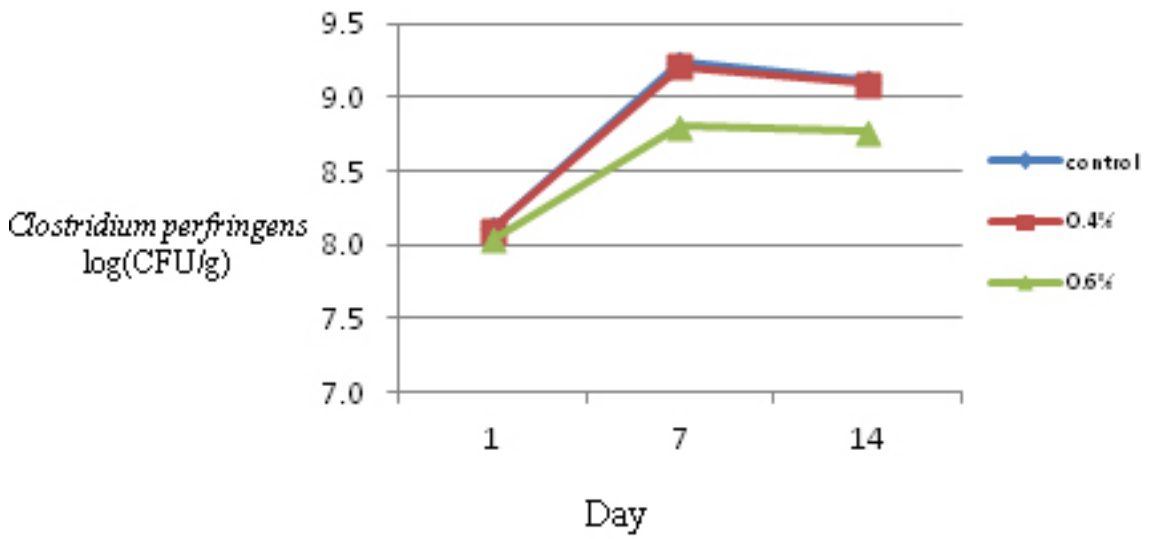

Graph 2: Effect of liquid smoke on the $C$. perfringens count 
Schwanke et al. (2007) investigated the antioxidant ability of liquid smoke made from Walnut wood on beef. Liquid smoke had a remarkable result in reduction of oxidation by affecting 2-thiobarbituric acid (TBARs), and liquid smoke did not have any significant effects on freshness, color, and aroma of the roasted beef. These results corresponded with the results of this research, but the effect of liquid smoke from walnut wood was greater. ${ }^{8}$

Martin et al. (2010) examined the effects of liquid smoke on cooked frankfurters inoculated with Listeria monocytogenes. The liquid smoke's $\mathrm{pH}$ in that research was 4.25-4.85, and $140 \mathrm{~d}$ of investigation showed that liquid smoke can stop the growth of Listeria monocytogenes for $130 \mathrm{~d}$, while applying 2 or $3 \mathrm{ml}$ of liquid smoke decreased 1 log of Listeria monocytogenes in within $12 \mathrm{~h}$. In the present research, the effect of liquid smoke on the growth of C. perfringens was proven. ${ }^{6}$
CaiKe-Zhou et al. (2011) investigated the effect of liquid smoke from American walnut tree wood on the oxidation, shelf life, and sensory properties of sausage. The results showed that application of $0.2 \%$ liquid smoke remarkably improved the sensory properties of the sausages, and $0.4 \%$ liquid smoke significantly reduced the peroxide value $(p<0.05)$ and had a significant effect in stopping microbial growth $(p<0.05)$. In the present study, a larger percentage of the liquid smoke was tried, up to $0.6 \%$.

Schwert et al. (2011) evaluated the effect of liquid and traditional smokes on the oxidation of lipids and proteins, and the sensory characteristics and color of cooked Brazilian sausage at temperatures of $5^{\circ} \mathrm{C}$ and $20^{\circ} \mathrm{C}$ over a time period of $120 \mathrm{~d}$. In that research, both traditional and liquid smokes reduced oxidation significantly $(p<0.05)$. Samples processed with liquid smoke had lower $b^{*}$ and higher $L^{*}$ when

Table 2: Given scores to sensory parameters in fumigated samples

\begin{tabular}{|c|c|c|c|c|c|c|}
\hline $\begin{array}{l}\text { Applied } \\
\text { concentration }\end{array}$ & score & $\begin{array}{c}\text { flavor } \\
\text { (frequencyby } \\
\text { number) }\end{array}$ & $\begin{array}{c}\text { odor } \\
\text { (frequency) }\end{array}$ & $\begin{array}{c}\text { color } \\
\text { (frequency) }\end{array}$ & $\begin{array}{l}\text { palatability } \\
\text { (frequency) }\end{array}$ & $\begin{array}{r}\text { acceptability } \\
\text { (frequency) }\end{array}$ \\
\hline 0.1 & 1 & 13 & 10 & 0 & 1 & 4 \\
\hline 0.1 & 2 & 5 & 7 & 1 & 1 & 14 \\
\hline 0.1 & 3 & 2 & 3 & 12 & 11 & 2 \\
\hline 0.1 & 4 & 0 & 0 & 6 & 6 & 0 \\
\hline 0.1 & 5 & 0 & 0 & 1 & 1 & 0 \\
\hline 0.2 & 1 & 2 & 2 & 0 & 0 & 0 \\
\hline 0.2 & 2 & 8 & 9 & 1 & 0 & 7 \\
\hline 0.2 & 3 & 9 & 8 & 11 & 13 & 12 \\
\hline 0.2 & 4 & 1 & 1 & 7 & 6 & 1 \\
\hline 0.2 & 5 & 0 & 0 & 1 & 1 & 0 \\
\hline 0.4 & 1 & 0 & 0 & 0 & 0 & 0 \\
\hline 0.4 & 2 & 0 & 4 & 0 & 0 & 0 \\
\hline 0.4 & 4 & 8 & 4 & 12 & 14 & 3 \\
\hline 0.4 & 4 & 7 & 9 & 7 & 5 & 11 \\
\hline 0.4 & 5 & 5 & 7 & 1 & 1 & 6 \\
\hline 0.6 & 1 & 0 & 0 & 0 & 0 & 0 \\
\hline 0.6 & 2 & 0 & 0 & 0 & 0 & 0 \\
\hline 0.6 & 3 & 2 & 1 & 10 & 10 & 0 \\
\hline 0.6 & 4 & 10 & 6 & 9 & 9 & 12 \\
\hline 0.6 & 5 & 8 & 13 & 1 & 1 & 8 \\
\hline
\end{tabular}


compared to traditional smoke processed samples, and the changes in $a^{*}$ were not remarkable. In the present study, using liquid smoke caused a decrease in the $L^{*}$ factor and an increase in the $a^{*}$ factor.

Arnim et al. investigated the impact of liquid smoke in concentrations of $0 \%, 3 \%, 5 \%$, and $7 \%$ over
$0 \mathrm{~d}, 5 \mathrm{~d}, 10 \mathrm{~d}$ and $15 \mathrm{~d}$ on the water content, protein content, fat content, $\mathrm{pH}$, and the total microbial count of meat balls. $\mathrm{pH}$ and moisture were significantly reduced, due to the presence of acetic acid, propionic acid, butyric acid, and formic acid. As an antimicrobial agent, liquid smoke inhibits the growth of proteolytic bacteria. Liquid smoke, during that research, caused

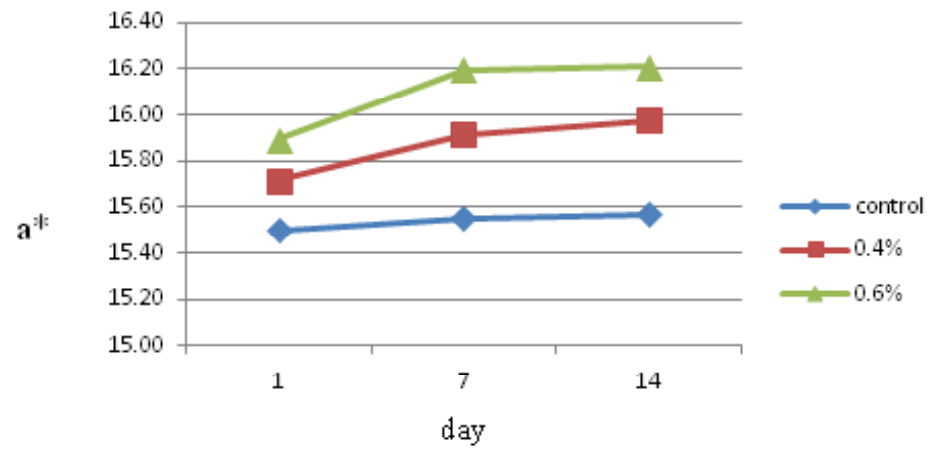

Graph 3: Effect of liquid smoke on $a^{*}$ of hotdog samples

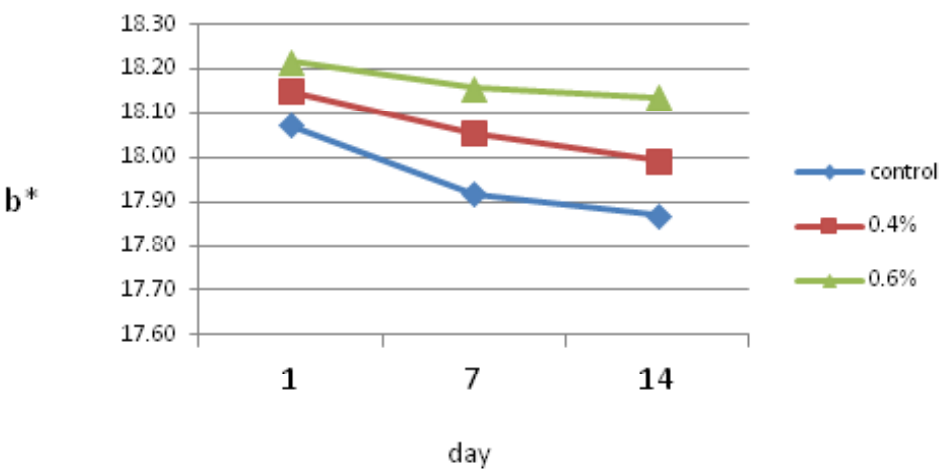

Graph 4: Effect of liquid smoke on $b^{*}$ of hotdog samples

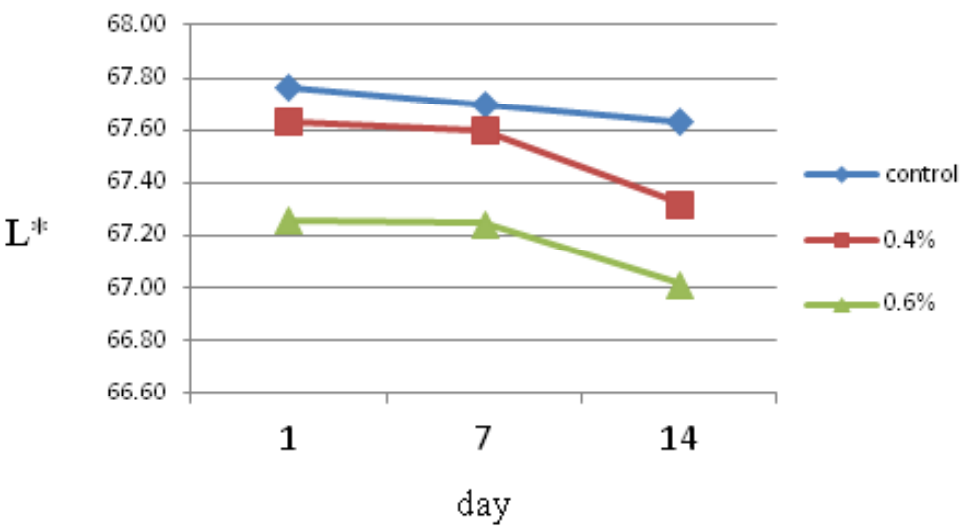

Graph 5: Effect of liquid smoke on $L^{*}$ of hotdog samples 
less of a reduction in the products' fat content, which was due to its antioxidant activity. In addition, the total microbial count of the product was reduced by the increased liquid smoke concentration, which showed a correspondence with the results of liquid smoke in this research.

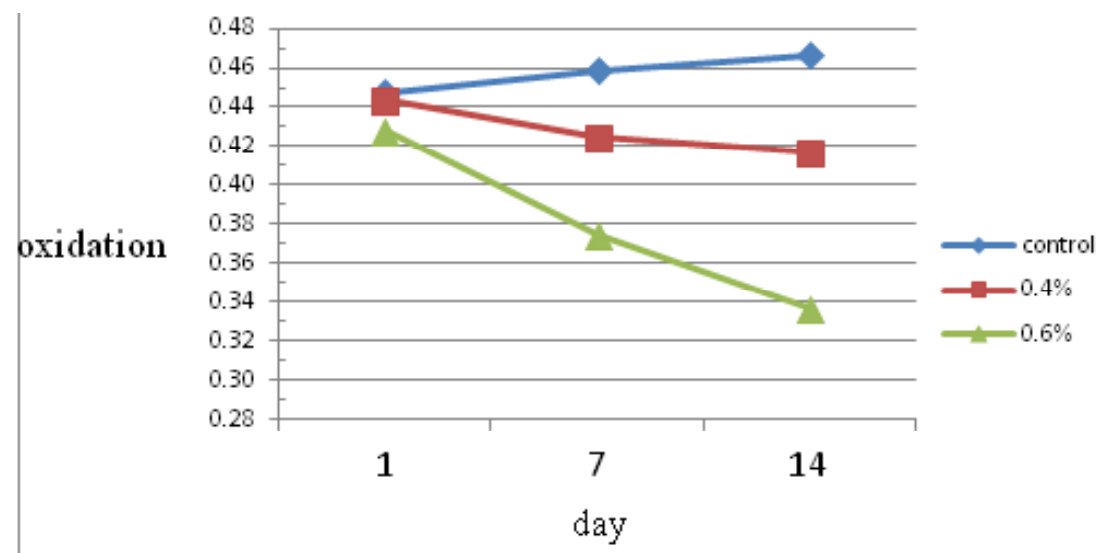

Graph 6: Effect of liquid smoke on the rate of oxidation in hotdog samples

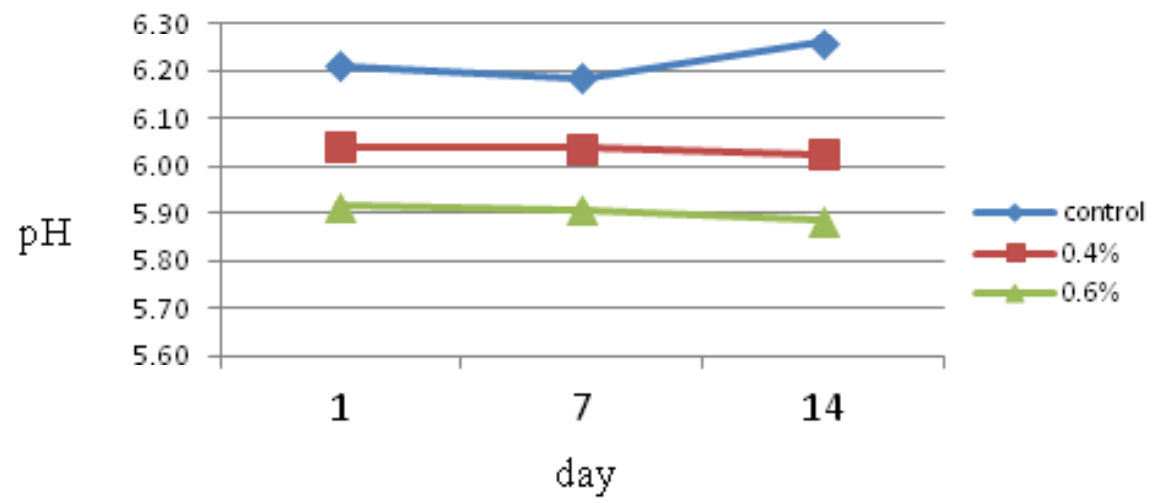

Graph 7: Effect of liquid smoke on the pH of hotdog samples

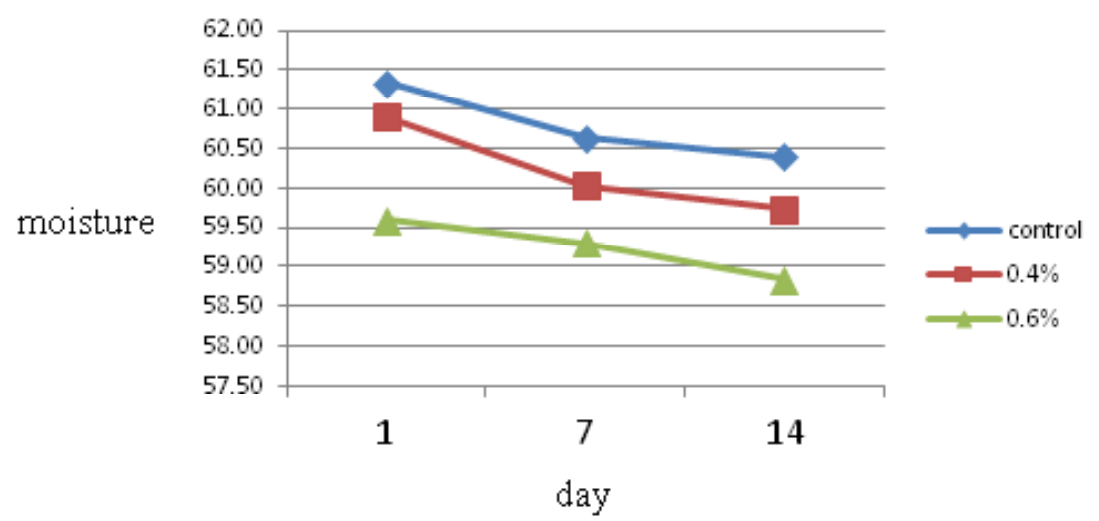

Graph 8: Effect of liquid smoke on moisture of hotdog samples 


\section{REFERENCES:}

1. Food safety regulators meet in Bangkok, Thailand. Releve epidemiologique hebdomadaire / Section d'hygiene du Secretariat de la Societe des Nations = Weekly epidemiological record / Health Section of the Secretariat of the League of Nations 2004, 79, 381-3.

2. Brown, A. N.; Cook, J. M.; Hammack, W. T.; Stepp, J. S.; Pelt, J. V.; Gerard, G., Analysis of pesticides residues in fresh produce using buffered acetonitrile extraction and aminopropyl cleanup with gas chromatography/ triple quadrupole mass spectrometry, liquid chromatography/triple quadrupole mass spectrometry, gas chromatography/ion trap detector mass spectrometry, and GC with a halogen-specific detector. Journal of AOAC International 2011, 94, 931-41.

3. Gedela, S.; Escoubas, J. R.; Muriana, P. M., Effect of inhibitory liquid smoke fractions on Listeria monocytogenes during longterm storage of frankfurters. Journal of food protection 2007, 70, 386-91.

4. Gedela, S.; Gamble, R. K.; Macwana, S.; Escoubas, J. R.; Muriana, P. M., Effect of inhibitory extracts derived from liquid smoke combined with postprocess pasteurization for control of Listeria monocytogenes on readyto-eat meats. Journal of food protection 2007 , 70, 2749-56.

5. Gonulalan, Z.; Kose, A.; Yetim, H., Effects of liquid smoke on quality characteristics of Turkish standard smoked beef tongue. Meat science 2004, 66, 165-70.

6. Martin, E. M.; O’Bryan, C. A.; Lary, R. Y., Jr.; Griffis, C. L.; Vaughn, K. L.; Marcy, J. A.; Ricke, S. C.; Crandall, P. G., Spray application of liquid smoke to reduce or eliminate Listeria monocytogenes surface inoculated on frankfurters. Meat science 2010, 85, 640-4.

7. Morey, A.; Bratcher, C. L.; Singh, M.; McKee, S. R., Effect of liquid smoke as an ingredient in frankfurters on Listeria monocytogenes and quality attributes. Poultry science 2012, 91, 2341-50.

8. Shashkov, M. V.; Sidelnikov, V. N., Mass spectral evaluation of column bleeding for imidazolium-based ionic liquids as GC liquid phases. Analytical and bioanalytical chemistry 2012, 403, 2673-82.

9. Pandey, S. K.; Kim, K. H., Evaluation of the solid-phase extraction (SPE) cartridge method in combination with thermal desorption-gas chromatography-mass spectrometry (TD-GCMS) for the analysis of different VOCs in liquid matrices in varying $\mathrm{pH}$ conditions. Journal of separation science 2012, 35, 1914-21.

10. Godayol, A.; Alonso, M.; Sanchez, J. M.; Antico, E., Odour-causing compounds in air samples: gas-liquid partition coefficients and determination using solidphase microextraction and GC with mass spectrometric detection. Journal of separation science 2013, 36, 1045-53.

11. de Bairros, A. V.; de Almeida, R. M.; Pantaleao, L.; Barcellos, T.; e Silva, S. M.; Yonamine, M., Determination of low levels of benzodiazepines and their metabolites in urine by hollow-fiber liquid-phase microextraction (LPME) and gas chromatography-mass spectrometry (GC-MS). Journal of chromatography. B, Analytical technologies in the biomedical and life sciences 2015, 975, 24-33.

12. Dunn, P. J.; Honch, N. V.; Evershed, R. P., Comparison of liquid chromatography-isotope ratio mass spectrometry (LC/IRMS) and gas chromatography-combustion-isotope ratio mass spectrometry (GC/C/IRMS) for the determination of collagen amino acid delta13C values for palaeodietary and palaeoecological reconstruction. Rapid communications in mass spectrometry : RCM 2011, 25, 2995-3011.

13. Fernandez-Fernandez, M.; RodriguezGonzalez, P.; Anon Alvarez, M. E.; Rodriguez, F.; Menendez, F. V.; Garcia Alonso, J. I., Simultaneous determination of creatinine and creatine in human serum by doublespike isotope dilution liquid chromatographytandem mass spectrometry (LC-MS/MS) and gas chromatography-mass spectrometry (GC-MS). Analytical chemistry 2015, 87, 3755-63.

14. Gao, B.; Qin, F.; Ding, T.; Chen, Y.; Lu, W.; Yu, L. L., Differentiating organically and conventionally grown oregano using 
ultraperformance liquid chromatography mass spectrometry (UPLC-MS), headspace gas chromatography with flame ionization detection (headspace-GC-FID), and flow injection mass spectrum (FIMS) fingerprints combined with multivariate data analysis. Journal of agricultural and food chemistry 2014, 62, 8075-84.

15. Hereu, A.; Bover-Cid, S.; Garriga, M.; Aymerich, T., High hydrostatic pressure and biopreservation of dry-cured ham to meet the Food Safety Objectives for Listeria monocytogenes. International journal of food microbiology 2012, 154, 107-12.

16. Kim, S. P.; Yang, J.Y.; Kang, M. Y.; Park, J. C.; Nam, S. H.; Friedman, M., Composition of liquid rice hull smoke and anti-inflammatory effects in mice. Journal of agricultural and food chemistry 2011, 59, 4570-81.
17. Nestola, M.; Thellmann, A., Determination of vitamins D2 and D3 in selected food matrices by online high-performance liquid chromatography-gas chromatography-mass spectrometry (HPLC-GC-MS). Analytical and bioanalytical chemistry 2015, 407, 297-308.

18. Roveri, F. L.; Paranhos, B. A.; Yonamine, M., Determination of phenobarbital in hair matrix by liquid phase microextraction (LPME) and gas chromatography-mass spectrometry (GC-MS). Forensic science international 2015, 265, 75-80.

19. Visciano, P.; Perugini, M.; Conte, F.; Amorena, M., Polycyclic aromatic hydrocarbons in farmed rainbow trout (Oncorhynchus mykiss) processed by traditional flue gas smoking and by liquid smoke flavourings. Food and chemical toxicology : an International journal published for the British Industrial Biological Research Association 2008, 46, 1409-13. 